\title{
Investigation on Reinforced Mechanism of Fiber Reinforced Asphalt Concrete Based on Micromechanical Modeling
}

\author{
Ying Gao, Qinglin Guo, Yanhua Guo, Pingchuan Wu, Wenqing Meng, and Tongye Jia \\ School of Civil Engineering, Hebei University of Engineering, Handan 056038, China \\ Correspondence should be addressed to Qinglin Guo; guoql@hebeu.edu.cn
}

Received 11 October 2016; Revised 3 December 2016; Accepted 25 December 2016; Published 18 January 2017

Academic Editor: Akihiko Kimura

Copyright (c) 2017 Ying Gao et al. This is an open access article distributed under the Creative Commons Attribution License, which permits unrestricted use, distribution, and reproduction in any medium, provided the original work is properly cited.

\begin{abstract}
Short fibers have been widely used to prepare the fiber reinforced asphalt concrete (FRAC). However, internal interactions between fiber and other phases of asphalt concrete are unclear although experimental methods have been used to design the FRAC successfully. In this paper, numerical method was used to investigate the reinforced mechanism of FRAC from microperspective. 2D micromechanical model of FRAC was established based on Monte Carlo theory. Effects of fiber length and content on stress state of asphalt mortar, effective modulus, and viscoelastic deformation of asphalt concrete were investigated. Indirect tensile stiffness modulus (ITSM) test and uniaxial creep test were carried out to verify the numerical results. Results show that maximum stress of asphalt mortar is lower compared to the control concrete when the fiber length is longer than $12 \mathrm{~mm}$. Fiber reduces the stress level of asphalt mortar significantly. Fiber length has no significant influence on the effective modulus of asphalt concrete. Fiber length and content both have notable impacts on the viscoelastic performance of FRAC. Fiber length should be given more attention in the future design of FRAC except the content.
\end{abstract}

\section{Introduction}

Asphalt concrete is a kind of composite including aggregate, asphalt, filler, and voids. It has been widely used for pavement construction in the world due to its good raveling performance. But pavement defects such as rutting, cracking, and moisture damage had plagued the designers and researchers all the way. In order to improve pavement service quality, many modifiers were added in asphalt concrete [1,2]. Among these modifiers, fiber reinforced technique has got more and more attentions as a result of its convenience [3].

So far, many kinds of fibers had been applied in asphalt concrete. These fibers included the steel fibers $[4,5]$, basalt fibers [6], polypropylene fibers [7, 8], glass fibers [9], natural fibers [10, 11], and thermoplastic fibers [12]. Among these researches, Chen and Xu [13] and Qian et al. [14] determined effects of polyester fiber, polyacrylonitrile fiber, lignin fiber, and aramid fiber on the asphalt binder. Chen and $\mathrm{Xu}$ [13] indicated that rutting resistance of the binder was improved by the fibers formed spatial network. Result of Qian et al. [14] revealed that fiber reinforced asphalt binder had a good low temperature ductility. However, Herráiz et al. [11] thought that fibers' behavior should be assessed in asphalt mixture although a general sight on the effect of fibers had been given by its characterization. So study on fiber reinforced binder only is an indirect evaluation.

In order to determine fibers' effect on asphalt mixtures directly, Serin et al. $[4,5]$ used steel fiber to modify the mixture. They suggested that the reinforced mixture had the best performance when the bitumen and fiber content were $5.5 \%$ and $0.75 \%$, respectively. Tapkin and Özcan $[7,15]$ and Kim and Park [8] carried out extensive analyses on polypropylene fibers reinforced mixture. Tapkin and Özcan $[7,15]$ indicated that polypropylene fibers not only reduced the accumulated creep strain but also improved the physical and mechanical properties of the mixture. Optimal fiber content for FRAC was $0.55 \%$ by the weight of aggregate. Kim and Park [8] proposed that optimal fiber content for recycled foamed asphalt concrete was $0.15 \%$. Morova et al. [16] stated that the optimal content of polyparaphenylene terephtalamide fiber was $0.25 \%$. Oda et al. [10] made a comparative analysis on the different FRACs. They indicated 
that natural fibers present excellent performance compared with polyester and cellulose fibers. Fiber increased the tensile strength and resilient modulus of asphalt mixture. On the study of crack resistance, Yoo and Kim [12] proposed an effective method to estimate the interfacial bond strength of plastic fibers. They indicated that interfacial bond strength between plastic fiber and the mixture was $0.12 \mathrm{Mpa}$, and fiber's contribution to resisting the failure was $25.5 \%$ approximately.

In China, performances of FRAC also were studied extensively. Chen et al. [17] investigated effects of polyester fiber, polyacrylonitrile fiber, and lignin fiber on the strength and fatigue behavior of asphalt concrete. It demonstrated that all fibers improved the rutting resistance, fatigue life, toughness, and ultimate flexural strain of asphalt concrete. Besides, rutting resistance and indirect tensile strength were best when the fiber content was $0.35 \%$. Xue et al. [18] studied the interface reinforced action and crack resistance of pavement straw composite fiber reinforced asphalt concrete. They thought that pavement straw composite fiber had a better interface reinforced action compared to the others. Ye et al. [19] pointed out that FARC had lower stiffness and higher flexibility. Few fibers reinforced mixtures had a better fatigue life than the control mixture. Fibers' effect on fatigue resistance of low stress level was more significant than that of the high level [20].

Based on the previous literatures review, we can find that the fiber improves the high temperature property, fatigue property, crack resistance, and toughness of asphalt mixture. Optimal fiber content also was different for each type of fiber. But the reinforced effects of all fibers were similar. Besides, these investigations were mainly focused on the influence of fiber content. However, García et al. [21] indicated that properties of mixtures such as air void and particle loss were related to the length and diameter of fibers. They also suggested that fibers for dense asphalt concrete should have certain geometries. Chen and $\mathrm{Xu}$ [13] also stated that fiber shape, size, and tensile strength also had noticeable impact on asphalt. Morova [22] also pointed out that the optimal basalt fiber content was $0.50 \%$ for the fiber with a length of $3.94 \mathrm{~mm}$. This was different from the result of Gao [23]. Gao [23] thought that the optimal fiber content was $0.07 \%$ and $0.15 \%$ for the ones of $9 \mathrm{~mm}$ and $6 \mathrm{~mm}$, respectively. Results of Fu et al. [24] and Park et al. [25] both showed that long fiber had better bridging action than the short one. Therefore, it can be concluded that fiber length also influences its reinforced ability. But load transferring ability of the fiber is mostly inferred based on the macro test results. Interactions among the mortar, fiber, and aggregate were so complex that they could not be revealed by the traditional test directly. Reinforced mechanism of fibers in the mixture was unclear although we have obtained the fibers distribution in the mixture [21]. Fortunately, micromechanical method is an effective technique to evaluate the internal mechanical behaviors of composites. It had been applied in asphalt concrete successfully [26-37].

Currently, discrete element method (DEM) and finite element method (FEM) are mainly applied to investigate the internal mechanical response of asphalt concrete. On the one hand, You et al. [27], Liu and You [28, 29], and Dai and You [30] analyzed the dynamic and creep properties of asphalt concrete based on discrete element modeling. They indicated that $3 \mathrm{D}$ computation is extremely time-consuming. So frequency-temperature superposition principle was suggested for DEM by them. On the other hand, Wang et al. [31-33] determined the voids distribution in asphalt concrete by X-ray CT scanning. Then micromechanical FE model was reconstructed based on the scanned images. Their results showed that modulus ratio, air voids, and loading orientation had significant impact on the strain state of mastic. Results of discrete and finite element simulation both agreed with the experimental results. For FRAC, fiber diameter is so small that it is very difficult to establish the fiber model in the discrete element simulation. Therefore, FEM was utilized to investigate the fibers' micromechanical reinforced mechanism in this study.

In this paper, micromechanical models of FRAC were established based on Monte Carlo theory. Effects of fiber length and content on the stress state of asphalt mortar, effective modulus, and viscoelastic deformation of mixture were investigated by finite element numerical analysis. Indirect tensile stiffness modulus test and creep test were carried out in order to verify the numerical results. Finally, variance analysis was made to determine the significant level of different factors.

\section{Theories and Methods}

2.1. Micromechanical Model Generation Algorithm. Until now, there are mainly two typical methods for micromechanical model establishment. One is based on digital image processing (DIP) technique [26-28, 30-32, 34, 35]. The other one is the random generated method which is based on Monte Carlo theory $[36,37]$. For the first one, digital image from camera or X-CT scanner was processed and then vector data was used to establish the model. Image processing and vector processing are so complicated that we must spend a lot of time on them although image describes the actual structure. Fortunately, Song et al. [38] proposed that the generated work of micromechanical model could be finished in several minutes. Guo et al. [39] also indicated that aggregate can be assumed as ellipsoidal particle. Hence, the second method was employed to generate the micromechanical model of FRAC in this paper. According to the studies of Dai and You [30], Wang et al. [36], and Yin et al. [37], aggregate can be simulated as elliptical particle in 2D analysis. In addition, Ioannis et al. [40] and Yu et al. [41] suggested that the short fiber also can be simulated as elliptical particle which had high aspect ratio in fiber reinforced composite. Therefore, aggregate and short fibers were both simulated as elliptical shape in this study.

For the aim of fast generation, overlapping of different aggregates and fibers should be avoided. The overlapping checking theory which is proposed by Song et al. [38] was adopted in this paper. For an ellipse, its center is $O_{0}\left(x_{0}, y_{0}\right)$, length of major axes is $2 a$; length of minor axes is $2 b$, the angle between the major axes and $x$-axis is $\alpha(\alpha \in[0, \pi])$, and the rotate matrix of ellipse can be written as follows:

$$
A=\left[\begin{array}{cc}
-\cos \alpha & \sin \alpha \\
\sin \alpha & \cos \alpha
\end{array}\right] \text {. }
$$


General equation of ellipse is shown in (2). The checking function is defined as (3). Consider

$$
\begin{aligned}
& \Gamma:\left(x-x_{0}, y-y_{0}\right) A\left[\begin{array}{cc}
\frac{1}{a^{2}} & 0 \\
0 & \frac{1}{b^{2}}
\end{array}\right] A^{\prime}\left[\begin{array}{l}
x-x_{0} \\
y-y_{0}
\end{array}\right]=1 \\
& \varphi(x, y) \\
& \quad=\left(x-x_{0}, y-y_{0}\right) A\left[\begin{array}{cc}
\frac{1}{a^{2}} & 0 \\
0 & \frac{1}{b^{2}}
\end{array}\right] A^{\prime}\left[\begin{array}{l}
x-x_{0} \\
y-y_{0}
\end{array}\right]-1,
\end{aligned}
$$

where, for any point $P\left(x_{1}, y_{1}\right)$, it locates outside of the ellipse if $\varphi\left(x_{1}, y_{1}\right)>0$; it locates on the ellipse if $\varphi\left(x_{1}, y_{1}\right)=$ 0 ; it locates inside of ellipse if $\varphi\left(x_{1}, y_{1}\right)<0$. Positional relationships between two ellipses are tangent, intersect, and separate. These relationships can be determined using the distance from the point $P$ to the ellipse. In this paper, a numerical searching method was used to calculate the minimum distance considering the computing efficiency. Ellipse was discreted to $n$ points using the parametric equation of ellipse. Minimum distance from the point $P$ to these discrete points was used for distance checking approximately. Distance from the point to ellipse can be calculated with the following equations:

$$
\begin{array}{ll}
\text { min. } & f(x, y)=\left(x-x_{1}\right)^{2}+\left(y-y_{1}\right)^{2} \\
\text { s.t. } & \left(x-x_{0}, y-y_{0}\right) A\left[\begin{array}{cc}
\frac{1}{a^{2}} & 0 \\
0 & \frac{1}{b^{2}}
\end{array}\right] A^{\prime}\left[\begin{array}{l}
x-x_{0} \\
y-y_{0}
\end{array}\right]=1 \\
d(P, \Gamma)=\sqrt{\min f(x, y)} .
\end{array}
$$

Moreover, the meshing of micromechanical model may be unsuccessful if the distance between two elliptical particles is very small. Considering the meshing need, distance between two elliptical particles was also checked. Micromechanical model of FRAC was established by two steps using the self-prepared program. Firstly, area percentages of aggregate and fibers were calculated according to the selected gradation. Then aggregates were randomly generated from the big to the small ones. Data of elliptical aggregate was stored when the generated aggregate did not overlap the previous particles. Secondly, short fiber was randomly generated and it was checked with previous generated aggregate and fibers until fiber fraction reached the set value. This process was conducted using the software MATLAB. Specific flowchart of self-prepared program was shown in Figure 1.

2.2. Numerical Simulation. Aggregate and fibers in the micromechanical model of FRAC can be generated using the prepared program. In this study, coarse aggregate which was larger than $2.36 \mathrm{~mm}$ was generated. Aspect ratio of aggregate was 1.45 according to our previous result [39]. Fine aggregate and asphalt binder were treated as asphalt mortar. As shown in Figure 2, the dense gradation AC-13 was selected

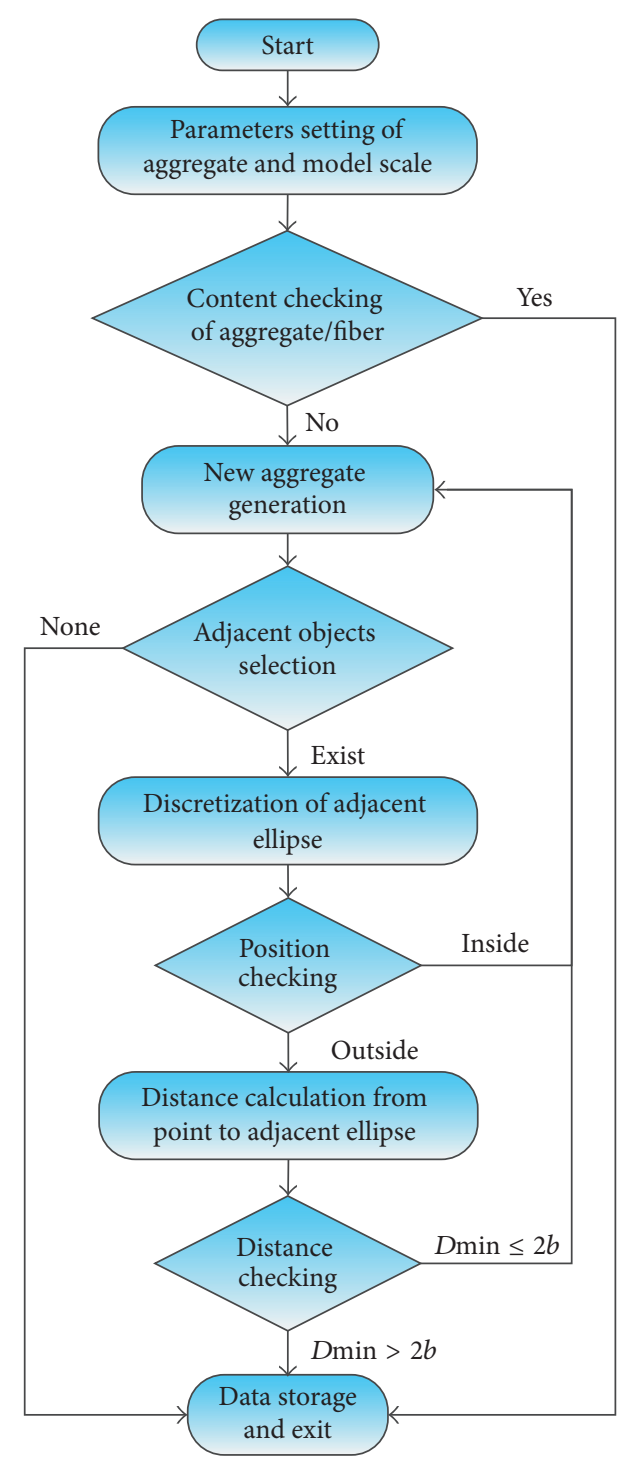

FIGURE 1: Flowchart of aggregate and fiber generation.

for investigation. Ma et al. [42] and Wang et al. [43] indicated that air void reduced the peak stress of asphalt concrete significantly. So air void was not considered in order to remove its disturbance on stress state and determine fibers' effect directly.

In accordance with the previous studies $[9,24]$, three fiber contents $(0.1 \%, 0.2 \%$, and $0.3 \%)$ and four fiber lengths $(3 \mathrm{~mm}$, $6 \mathrm{~mm}, 12 \mathrm{~mm}$, and $15 \mathrm{~mm}$ ) were selected. In 2D analysis, area percentage of fiber (APF) was used to control the fiber content. Ratio of fiber area to specimen area was defined as APF in this paper. Fiber diameter $0.03 \mathrm{~mm}$ was selected according to the size of glass fibers. Maximum running time of model generation process was 7.4 hours on the computer with $8 \mathrm{G}$ RAM and $3.4 \mathrm{GHz}$ CPU. Typical models of FRAC were shown in Figure 3, where APF represents the area percentage of fiber. $L f$ is the fiber length.

Finite element method (FEM) was used to conduct the numerical analysis when model data of FRAC was obtained. 


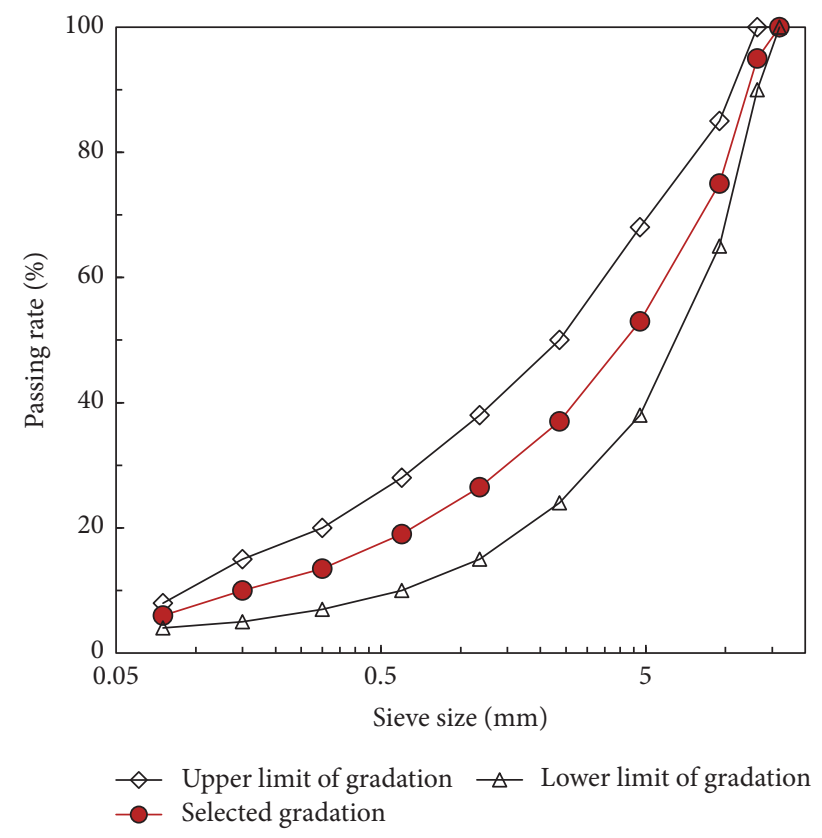

FIGURE 2: Selected gradation for numerical and experimental tests.

The general software ANSYS was adopted to establish the finite element model. Direct tensile test and uniaxial creep test have been used to evaluate the elastic performance and viscoelastic property of asphalt concrete [12, 24, 26, 37]. Therefore, they were adopted to investigate the stress state and effective properties of FRAC in this paper. For each type of FRAC, 6 numerical specimens were prepared utilizing the self-prepared program. Elastic modulus of asphalt mortar was tested by uniaxial compaction test at $-10^{\circ} \mathrm{C}$. Elastic properties of aggregate, mortar, and fiber were listed in Table 1. Schematics of numerical test were shown in Figure 4.

2.3. Statistical Analysis on Stress State of Asphalt Mortar. Aggregate and fibers were randomly distributed in FRAC. This will cause the stress variation of asphalt mortar in different areas. Dong et al. [35] and Wang et al. [36] indicated that the failure was mainly generated in asphalt mortar. Therefore, statistical analysis was made on the elements of asphalt mortar in order to evaluate the fibers' effect on FRAC. Besides, Castillo and Caro [44], Yang et al. [45], and Guo [46] had indicated that stress and strain in random area closely followed the Gaussian model. So, Gaussian model was used to describe the stress state of mortar phase. In this paper, the element equivalent stress of asphalt mortar was statistically analyzed to evaluate fibers' influence on the internal stress state. Gaussian equation is as follows:

$$
P(x)=a \exp \left(-\frac{(x-b)^{2}}{c}\right),
$$

where $P(x)$ is the probability density function (PDF); $a$ is the probability density parameter. $b$ is the median value of variable $x . c$ expresses the deviation of variable $x$. Parameters $a, b$, and $c$ for probability density function of equivalent stress were obtained using the curve fitting method.
TABLE 1: Elastic properties of different materials.

\begin{tabular}{lcc}
\hline Material & Elastic modulus $(\mathrm{MPa})$ & Poisson ratio \\
\hline Asphalt mortar & 710 & 0.30 \\
Aggregate & 25000 & 0.20 \\
Fiber & 73000 & 0.22 \\
\hline
\end{tabular}

\section{Materials and Experiment}

3.1. Materials. In this study, the asphalt AH-90\# was used to prepare the mortar and concrete. Its properties were listed in Table 2. As shown in Figure 5, short glass fiber which is from Taishan Fiberglass Inc., Shandong Province, China, was used to prepare FRAC. Its properties were presented in Table 3.

As presented in Table 4, apparent specific gravities of aggregate were tested according to the Standards ASTM-C127 and C128. Optimum asphalt contents for FRAC and asphalt mortar were $4.8 \%$ and $11.8 \%$, respectively. Dry method was used to prepare FRAC in this study. Firstly, hot aggregates and asphalt were mixed about $90 \mathrm{~s}$ at $170^{\circ} \mathrm{C}$, and then glass fiber was added to the mixture and mixed for $90 \mathrm{~s}$. Secondly, mineral filler was added and mixed for $90 \mathrm{~s}$ again. And all the processing time should not exceed 6 minutes in order to prevent asphalt aging.

3.2. Indirect Tensile Stiffness Modulus (ITSM) Test. Pettinaria et al. [47] and Guo et al. [9] indicated that the stiffness of asphalt mixture was always considered as a synthetic indicator of structural properties. Therefore, indirect tensile stiffness modulus (ITSM) test was used to investigate the stiffness modulus of FRAC at $5^{\circ} \mathrm{C}$ according to the Standard EN 12697-26 [48]. A testing machine named Cooper NU-14 was used to perform the test. Three specimens were prepared for each type of asphalt concrete. And the size of specimen is $\varphi 101.6 \mathrm{~mm} \times 63.5 \mathrm{~mm}$. Specimens were placed in the chamber at test temperature for $6 \mathrm{~h}$ before test. The loading schematic was shown in Figure 6. Rise time of impulse is $124 \mathrm{~ms}$. Load duration period from the start of one impulse to the next is $3.0 \mathrm{~s}$. The target deformation in horizontal direction is $5 \mu \mathrm{m}$. The peak load was adjusted according to the tested target deformation during the test. Data of five impulses were acquired after adjustment.

The stiffness modulus can be calculated with the following equation:

$$
S_{m}=\frac{F \times(\mu+0.27)}{h \times Z},
$$

where $S_{m}$ is the indirect tensile stiffness modulus, $\mathrm{MPa} ; F$ is the peak load, $\mathrm{N}$; Poisson ratio $\mu$ is 0.25 at $5^{\circ} \mathrm{C}$. $Z$ is the deformation in horizontal direction, $\mathrm{mm} ; h$ is the height of specimen, $\mathrm{mm}$.

3.3. Creep Test. In order to verify the fibers' influence on the viscoelastic performance, creep test was conducted on asphalt mortar and concrete using Cooper NU-14 at $20^{\circ} \mathrm{C}$. Three specimens were used for each test. Sizes of mortar specimen and concrete specimen were $\varphi 50 \mathrm{~mm} \times 50 \mathrm{~mm}$ and $\varphi 75 \mathrm{~mm} \times 100 \mathrm{~mm}$, respectively. Specimens were placed in 

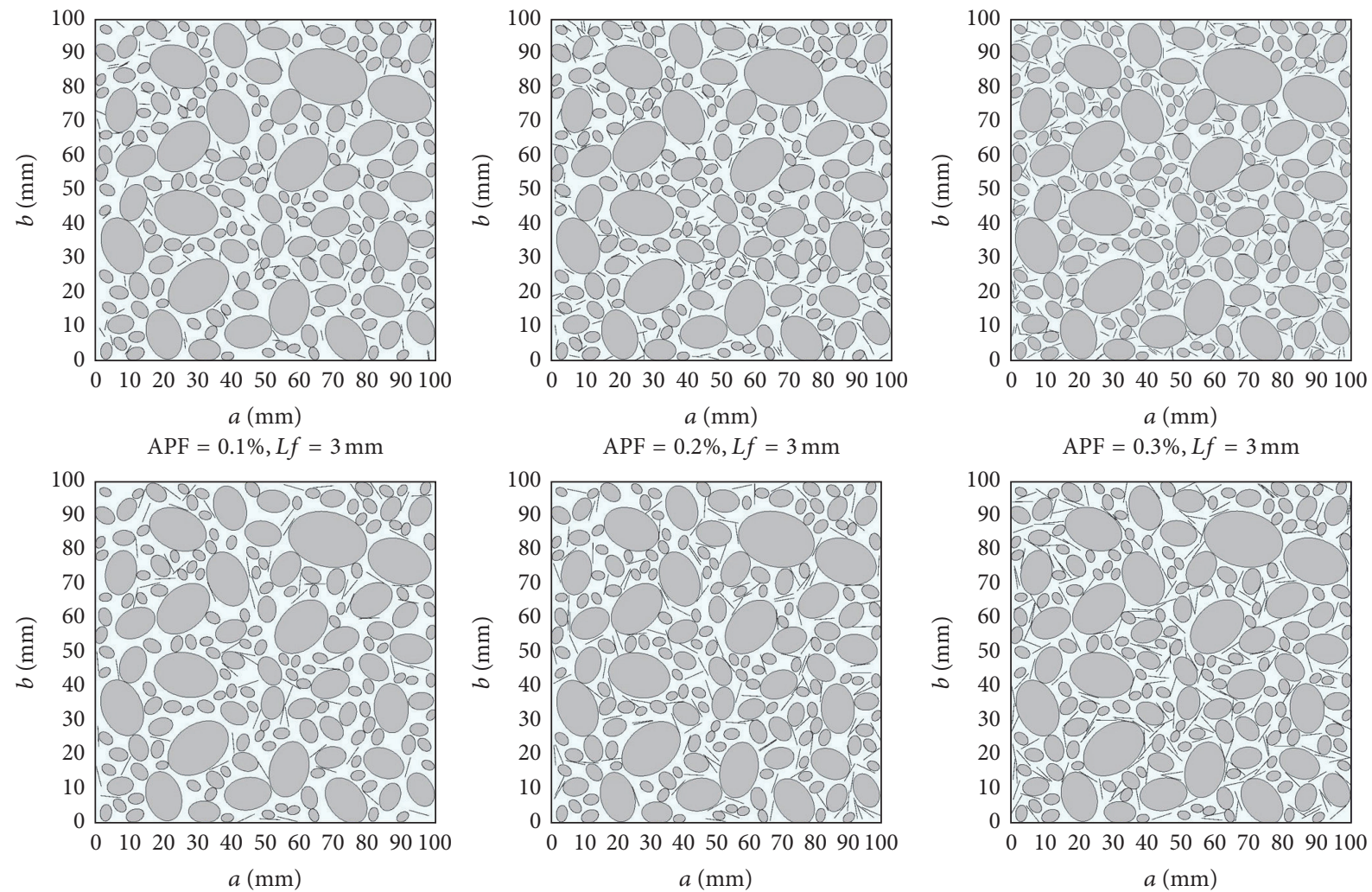
$a(\mathrm{~mm})$
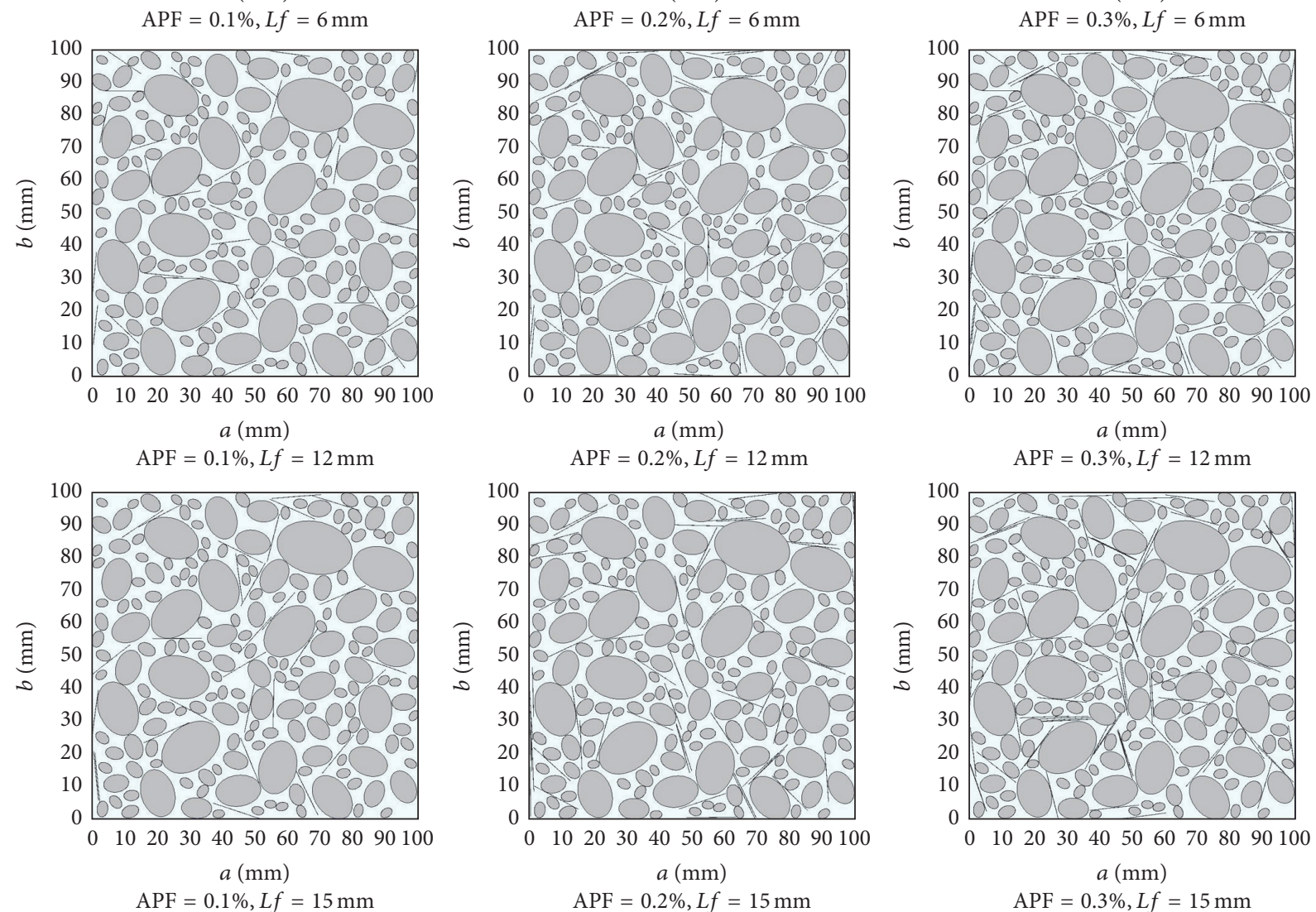

FIgURE 3: Micromechanical models of FRAC. 


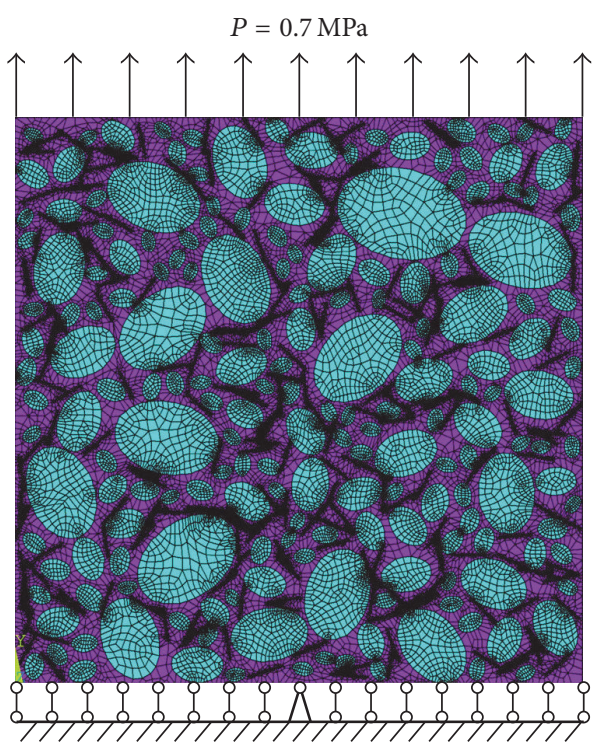

(a) Direct tensile test

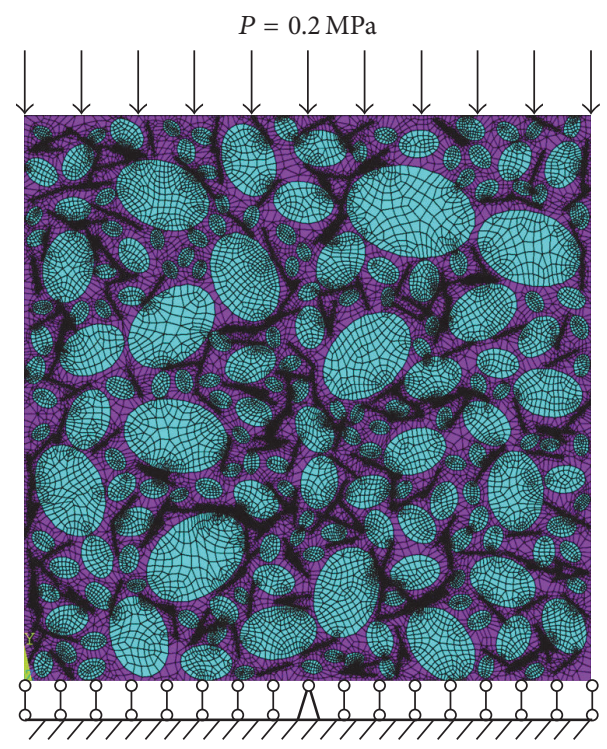

(b) Uniaxial creep test

Figure 4: Schematics of numerical tests.

TABLE 2: Properties of asphalt.

\begin{tabular}{lcccc}
\hline Property & Penetration $\left(25^{\circ} \mathrm{C}, 0.1 \mathrm{~mm}\right)$ & Ductility $\left(15^{\circ} \mathrm{C}, \mathrm{cm}\right)$ & Softening point $\left({ }^{\circ} \mathrm{C}\right)$ & Penetration index \\
\hline Value & 86 & 168.5 & 44.5 & -1.416 \\
\hline
\end{tabular}

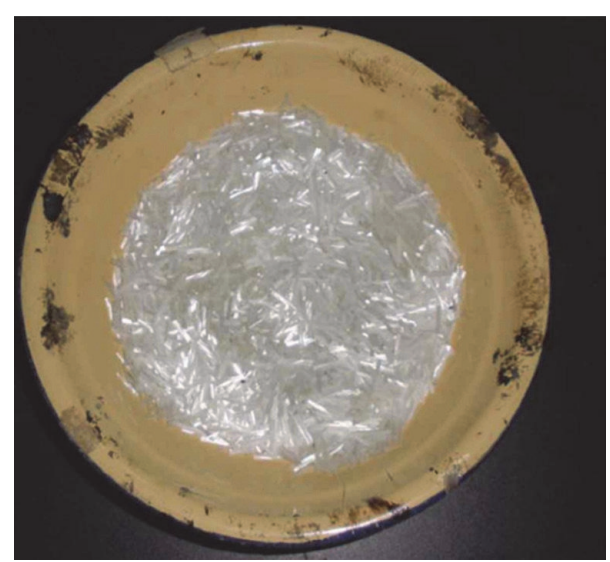

FIGURE 5: Glass fibers for experiment.

the chamber at $20^{\circ} \mathrm{C}$ for $6 \mathrm{~h}$ before test. The load and duration time of creep test were $0.2 \mathrm{Mpa}$ and $1200 \mathrm{~s}$, respectively. At the beginning of test, the precompressive load $0.01 \mathrm{Mpa}$ was applied for $30 \mathrm{~s}$ and then test load was instantaneously applied on the specimen until the test finish. Creep deformation at the top of specimen was recorded during the test. Test procedures were shown in Figure 7. After the test, Prony parameters of asphalt mortar were obtained by curve fitting, and they were listed in Table 5.

\section{Results and Discussion}

4.1. Stress State of Asphalt Mortar. Wang et al. [49] had indicated that there was significant stress concentration in asphalt concrete. This phenomenon was mainly generated in mortar phase. Therefore, numerical direct tensile test was conducted to determine the fibers' effect on asphalt mortar. In this study, the maximum equivalent stress (MAXES) of mortar elements was used to evaluate the stress concentration firstly. Results of MAXES were shown in Figure 7.

As shown in Figure 8, it can be found that the maximum equivalent stresses of asphalt mortar are all greater than 3.0 MPa in micromodels. But the maximum equivalent stress is $0.7 \mathrm{MPa}$ in the traditional homogeneous model. Consequently, the actual MAXES in asphalt concrete is higher than that in the assumption of homogeneous material. Additionally, MAXES decreases gradually with the increasing of fiber length and content. MAXES of FRAC is higher than the control one when the fiber length is $3 \mathrm{~mm}$, and it is lower than the control one when the fiber is longer than $12 \mathrm{~mm}$. It means that long fiber is more effective in reducing the stress concentration than the short one. The longer the fiber is, the lower the stress level is. In accordance with the viewpoint of Naaman and Reinhardt [50], the random distributed fiber is helpful for dispersing the localized damage. Herein, the damage in FRAC can be reduced by the change of stress state. Stress concentration can not be reduced if the fiber is too short. In brief, fiber length should be considered carefully in the design of FRAC in order to control the mortar stress under the vehicle action.

Moreover, equivalent stresses of all mortar elements were statistically analyzed using Gaussian model in order to evaluate the overall effect of fibers on the mortar phase [46, 49]. Parameters $a, b$, and $c$ of Gaussian model were obtained by curve fitting. Correlation coefficients of the fitting were all 

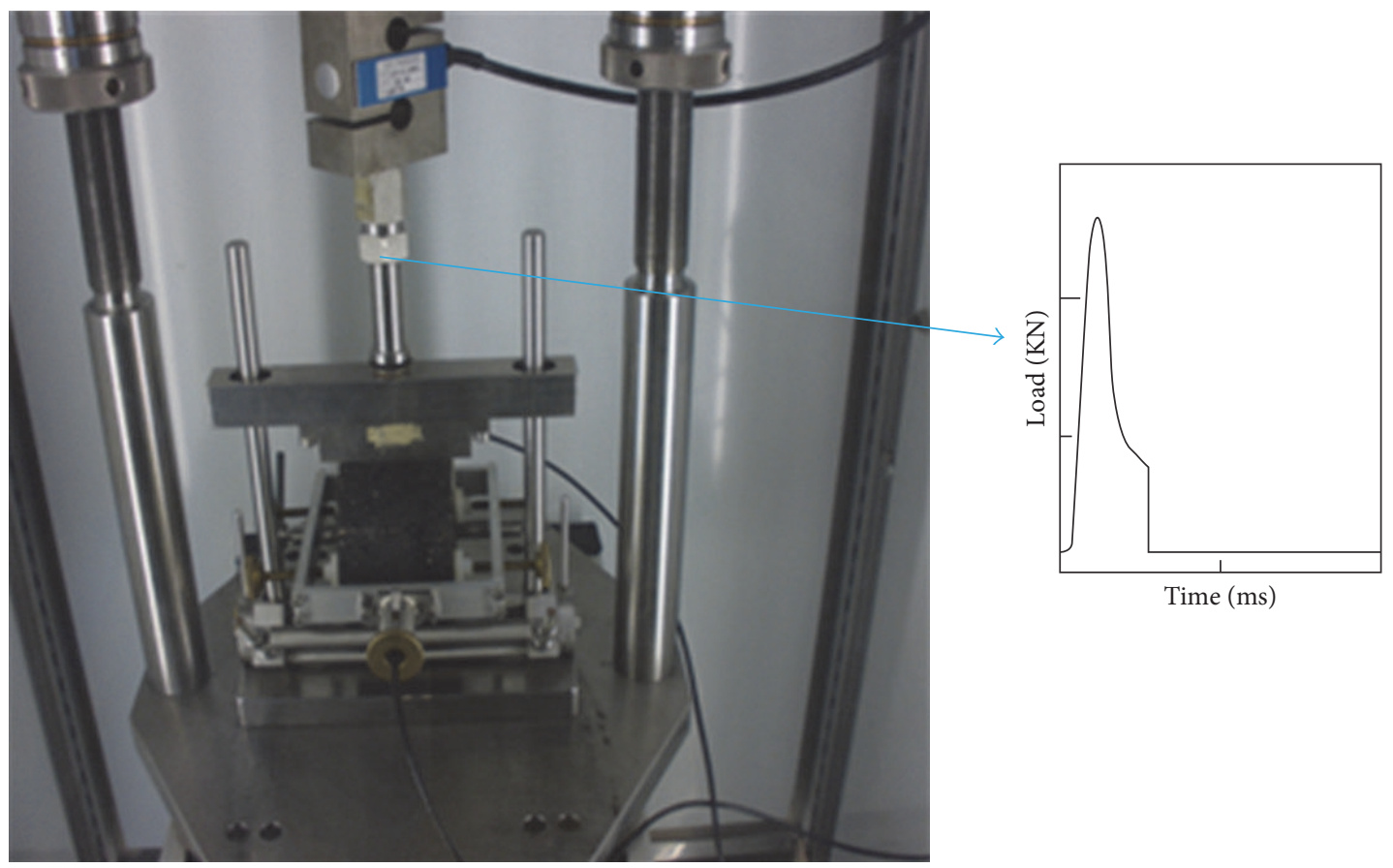

FIGURE 6: Indirect tensile stiffness modulus test.

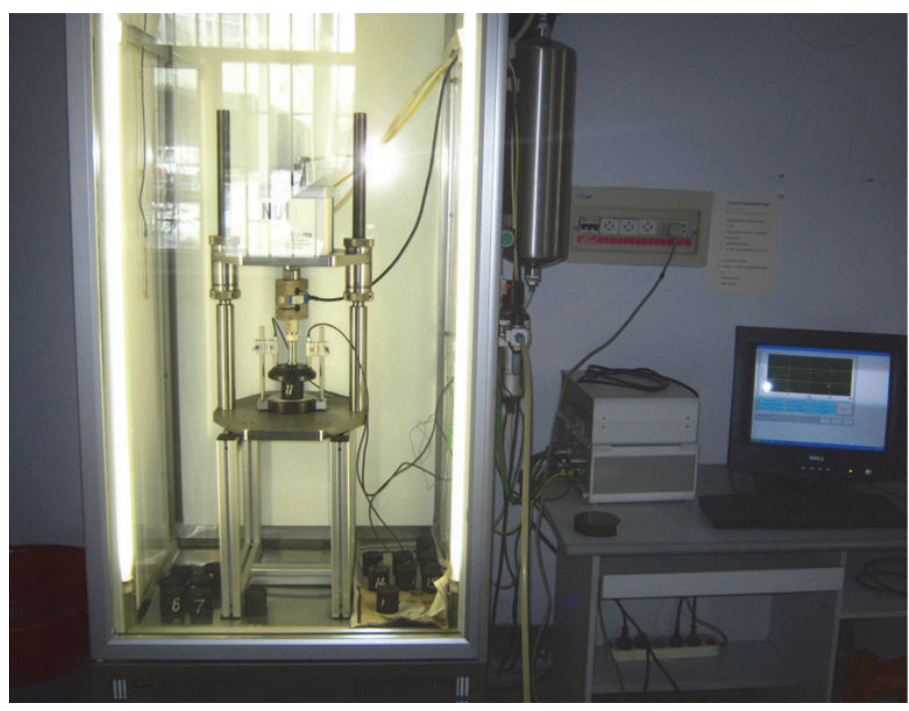

(a) Asphalt mortar

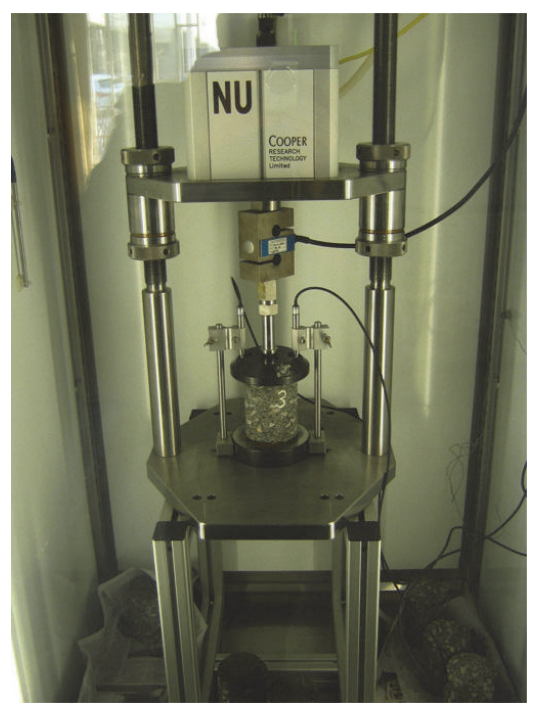

(b) Asphalt concrete

FIgURE 7: Creep test procedures.

TABLE 3: Physical properties of glass fiber.

\begin{tabular}{lcccccc}
\hline Property & $\begin{array}{c}\text { Length } \\
(\mathrm{mm})\end{array}$ & $\begin{array}{c}\text { Specific gravity } \\
\left(\mathrm{g} / \mathrm{cm}^{3}\right)\end{array}$ & Color & $\begin{array}{c}\text { Melting } \\
\text { temperature } \\
\left({ }^{\circ} \mathrm{C}\right)\end{array}$ & $\begin{array}{c}\text { Tensile strength } \\
(\mathrm{MPa})\end{array}$ & $\begin{array}{c}\text { Ultimate tensile } \\
\text { strain } \\
(\%)\end{array}$ \\
\hline Value & 12 & 2.5 & White & $>1500$ & $3100-3400$ & $3.3-3.6$
\end{tabular}

TABLE 4: Apparent specific gravities of aggregate.

\begin{tabular}{|c|c|c|c|c|c|c|c|c|c|}
\hline Sieve size $(\mathrm{mm})$ & 13.2 & 9.5 & 4.75 & 2.36 & 1.18 & 0.6 & 0.3 & 0.15 & 0.075 \\
\hline $\begin{array}{l}\text { Apparent specific gravity } \\
\left(\mathrm{g} / \mathrm{cm}^{3}\right)\end{array}$ & 2.817 & 2.704 & 2.821 & 2.655 & 2.689 & 2.645 & 2.652 & 2.710 & 2.682 \\
\hline
\end{tabular}


TABLE 5: Prony parameters of asphalt mortar.

\begin{tabular}{lcccrr}
\hline Parameter & & & $i$ & \\
& $\infty$ & 1 & 2 & 3 & 4 \\
\hline$E_{i}(\mathrm{MPa})$ & 15.01 & 143.90 & 17.74 & 6.65 & 100 \\
$\tau_{i}(\mathrm{~S})$ & - & 1 & 10 & 1000 \\
\hline
\end{tabular}

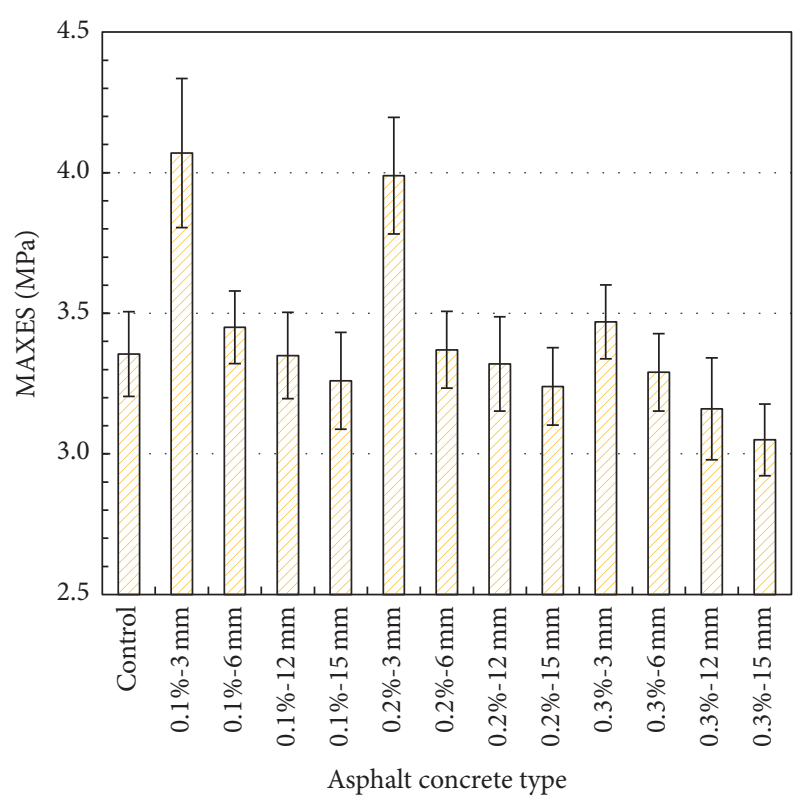

FIGURE 8: Maximum equivalent stress of asphalt mortar.

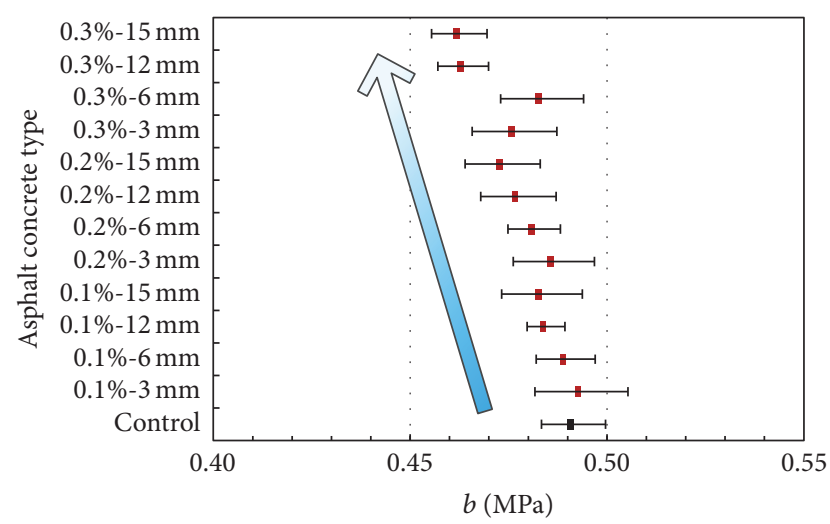

Figure 9: Parameter $b$ for different asphalt concrete.

greater than 0.985. As shown in Figure 9, parameter $b$ was used to estimate the stress level of mortar in FRAC because it represents the median value of equivalent stress.

It can be seen form Figure 9 that the median equivalent stress of FRAC is less than that of the control one. $b$ drops with the increasing of fiber content obviously. The more the content is, the lower the median equivalent stress is. It means that stress level of asphalt mortar was reduced by the fiber. This confirms the inference of Fu et al. [24]. Park et al. [25] had stated that the applied force was transferred through the

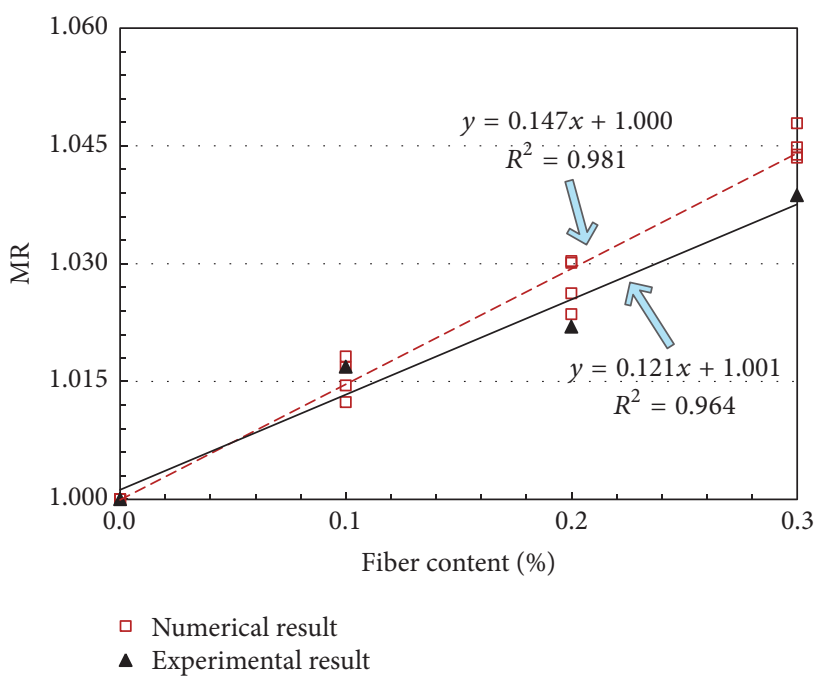

FIGURE 10: Modulus ratios of numerical and experimental tests.

fiber-matrix interface. A higher surface area of fiber provided a better reinforcing effect. More fiber content will lead to a higher surface area, and this causes the rise of fibers' load transferred ability. Moreover, median equivalent stress $b$ of the mortar at a given fiber content also decreases with the increase of fiber length. It reveals that long fiber results in a better overall behavior. Long fiber has more chance to form fiber-aggregate-mortar interlocking structure than the short one [25]. The interlocked structure also bears the load partly. In a word, fiber reduces the stress level of asphalt mortar indeed. Besides, Wu et al. $[19,20]$ indicated that the fatigue failure was always generated in asphalt mortar. Fatigue life of asphalt concrete was dependent on the life of asphalt mortar. Guo et al. [9] indicated that the fatigue life at low stress level is longer than that of high stress level obviously. Therefore, it can be concluded that fatigue life improvement of FRAC is mainly induced by the decrease of mortar stress.

4.2. Effective Modulus Ratio. For asphalt concrete, there are many methods to conduct modulus test [51]. Moduluses obtained from different tests also were different, and comparative analysis on these data can not be made directly. Therefore, Peng et al. [52] and Guo et al. [9] utilized modulus ratio to evaluate the reinforced effect of modifiers. In this paper, modulus ratio (MR) was defined as the modulus of FRAC to that of control one in order to determine fibers' effect on effective modulus of asphalt concrete. Modulus ratios of numerical and experimental test were obtained from direct tensile test (DTT) and ITSM test, respectively. Both ratios were shown in Figure 10. 

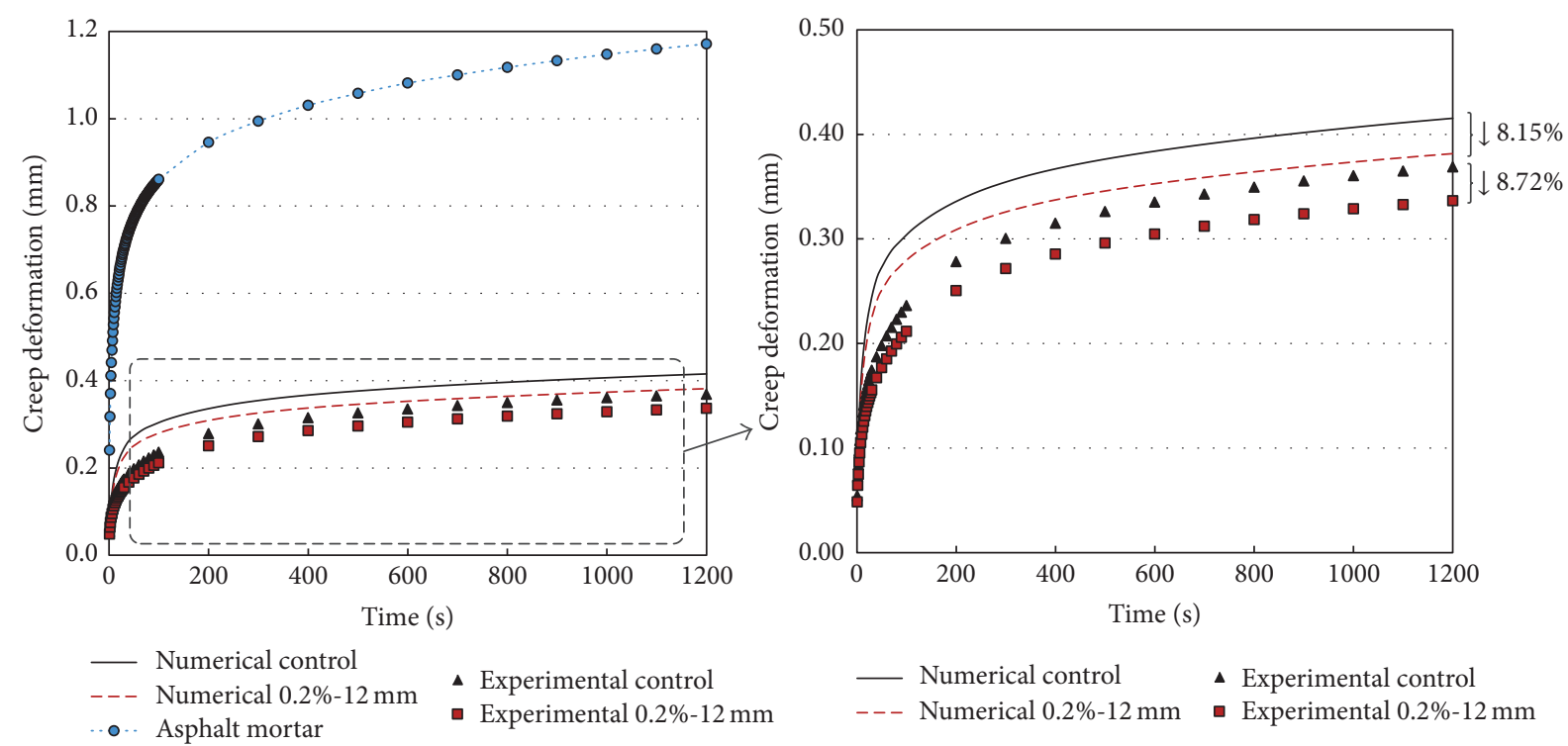

FIGURE 11: Comparison of experimental and numerical results.

As shown in Figure 10, the numerical MRs are consistent with the experimental one. It means that the numerical result is correct. Numerical and experimental modulus ratios both increase with fiber content. Regressive correlation coefficients of them are both greater than 0.95 . There is a good linear relationship between modulus ratio and fiber content. So fiber content has considerable impact on the modulus of asphalt concrete. However, effect of fiber length on modulus is not obvious. This may be attributed to the following two reasons. On one hand, Tan et al. [53] indicated that the deformation of asphalt concrete was mainly induced by the deformation of mortar. As previous description, mortar stress of FRAC moves to the low level due to fibers' load transferring action. This results in the decline of effective strain. Finally, modulus of FRAC increases. On the other hand, the selected fiber is glass fiber in this study. Its modulus is greater than the mortar. Fiber also is a kind of rigid inclusion in FRAC. This may also cause the increasing of effective modulus.

4.3. Creep Deformation. It had been declared that short fiber was helpful to reduce the viscoelastic deformation of asphalt concrete $[7,15,24]$. However, effect of fiber length on that was unclear although the influence of content has been determined by experiment. Accordingly, numerical creep test was conducted and verified by uniaxial creep test. Experimental and numerical results were shown in Figure 11.

As shown in Figure 11, creep deformation of the mortar at $1200 \mathrm{~s}$ is about 2.8 times that of asphalt concrete. Creep deformation of asphalt concrete decreases when the fiber is added. Deformations of numerical and experimental tests have dropped $8.15 \%$ and $8.72 \%$, respectively. Relative error between the numerical and experimental ones is $6.5 \%$. It means that numerical result is correct and accurate. In addition, the numerical deformations are all higher than the experimental ones. This is because the transverse reinforced action in the third dimension is not considered in 2D analysis.

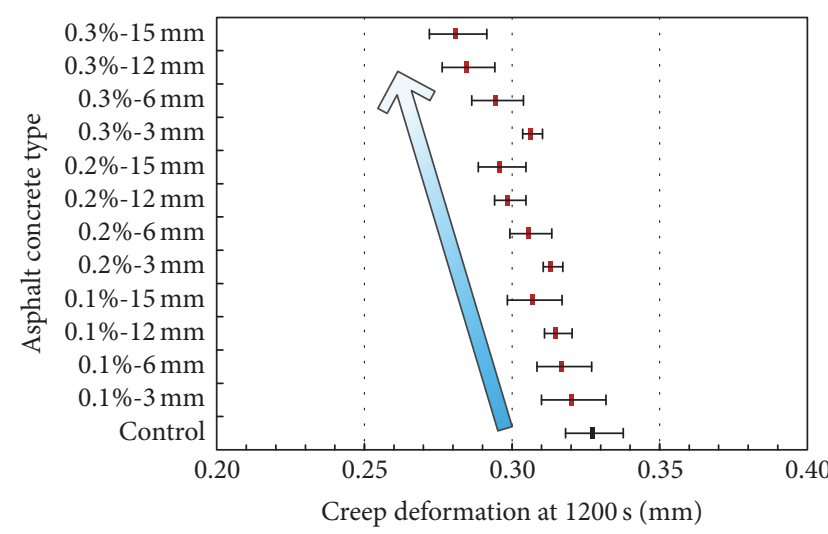

FIGURE 12: Creep deformations of different asphalt concrete.

Creep deformations of all concrete were obtained through numerical creep test, as shown in Figure 12.

It can be seen from Figure 12 that creep deformation decreases with the increases of fiber content and length. The more the fiber content is, the lower the creep deformation is. The longer the fiber is, the lower the creep deformation is. Creep deformation drops about $14.1 \%$ for the type of $0.3 \%$ $15 \mathrm{~mm}$. Decline of creep deformation is mainly caused by the following reasons. Firstly, Katman et al. [54] had indicated that the stress level affected its viscoelastic deformation significantly. Mortar stress moves to the low level under the bridging action of fibers. So a lower stress leads to a lower creep deformation. Secondly, Putman and Amirkhanian [55] and Hassan and Al-Jabri [56] proposed that fibers have good stabilizing effects on the mortar. So the fibers' stabilized ability also reduces the viscoelastic deformation at a certain degree.

4.4. ANOVA Analysis. On the basis of the above analysis, it reveals that fiber influences the stress state, effective modulus, 
TABLE 6: Two-factor ANOVA on the properties of FRAC $(\alpha=0.05)$.

\begin{tabular}{|c|c|c|c|c|c|}
\hline Item & Source of variance & $F$ & $P$ value & $F$-crit & Significant \\
\hline \multirow{2}{*}{ MAXES } & Fiber content & 7.01 & 0.027 & 5.14 & Yes \\
\hline & Fiber length & 18.95 & 0.002 & 4.76 & Yes \\
\hline \multirow{2}{*}{$b$} & Fiber content & 15.56 & 0.004 & 5.14 & Yes \\
\hline & Fiber length & 7.26 & 0.020 & 4.76 & Yes \\
\hline \multirow{2}{*}{ MR } & Fiber content & 116.51 & 0.000 & 5.14 & Yes \\
\hline & Fiber length & 0.74 & 0.568 & 4.76 & No \\
\hline \multirow{2}{*}{ Creep deformation } & Fiber content & 30.41 & 0.001 & 5.14 & Yes \\
\hline & Fiber length & 8.98 & 0.012 & 4.76 & Yes \\
\hline
\end{tabular}

and viscoelastic deformed property of asphalt concrete. But the significance of different factors was unknown. In order to provide a better understanding of fiber's effect, statistical analysis of variance (ANOVA) method was employed to investigate their significance. In this paper, two-factor analysis of variance without replication was adopted. According to the previous studies $[9,57]$, the significance level $(\alpha)$ in this investigation was 0.05 . F-tests were performed at the confidence level 95\%. Results were listed in Table 6.

As shown in Table $6, P$ values of MAXES and $b$ and creep deformation are all less than the significance level $\alpha$. Their $F$ values are all higher than the critical value ( $F$-crit). It means that fiber content and length both have significant influences on the stress state and creep deformation. This is different from the result of Fu et al. [24]. So fiber length should be given more attention in the future design. Besides, it should be noted that $P$ values of MR for fiber content are less than 0.05 , but the value for fiber length is greater than 0.05. Park et al. [25] had indicated that fiber had no obvious effect on the modulus when fiber diameter is less than $0.1 \mathrm{~mm}$. Hence, influence of fiber length on effective modulus is not significant when the fiber diameter is slender. The change of modulus is only caused by fiber content.

\section{Conclusions}

In this paper, influences of fiber length and content on elastic and viscoelastic properties of asphalt concrete were investigated using micromechanical numerical method. The following conclusions can be drawn based on the above study.

(i) Short fiber reduces the maximum stress and stress level of asphalt mortar. Fiber length and content both have significant effects on stress state. Long fiber has better stress transferring action than the short one. The more and the longer fiber is, the lower the mortar stress is. Decline of stress intensity is beneficial to improve the fatigue life of asphalt concrete.

(ii) Short fiber has a slight influence on the effective modulus of FRAC. Effective modulus ratio only increases with fiber content. Impact of fiber length on effective modulus is not significant when fiber diameter is very small.

(iii) Viscoelastic deformed performance was improved by the fiber notably. Fiber content and length both have significant effects on the creep property. Decline of creep deformation was caused by the decrease of mortar stress and the fibers' stabilized action. Fiber is helpful for reducing the pavement rutting deformation at high temperature.

(iv) There is a good agreement between the numerical and test results. Meso numerical method is an accurate and convenient method for the analysis of composite materials such as asphalt concrete. In $2 \mathrm{D}$ numerical investigation, short fiber can be simulated as elliptical particle with a high aspect ratio.

In brief, fiber length is an important factor for FRAC beyond the content. It also influences the performance of FRAC obviously. Fiber length should be considered in the design and actual application of FRAC. Moreover, it should be noticed that the work of this paper was only based on 2D perspective. Effects of fiber on other properties such as cracking and fatigue resistance were unclear yet. Effect of fiber on the third dimension of FRAC also was not determined. Hence, a prospective study should focus on $3 \mathrm{D}$ modeling and behaviors of cracking and fatigue resistance of FRAC. 3D simulation should be performed to evaluate the transverse reinforced ability of fibers further.

\section{Competing Interests}

The authors declare that there is no conflict of interests regarding the publication of this paper.

\section{Acknowledgments}

The authors express their appreciation for the financial support of National Natural Science Foundation of China under Grant no. 51508150 and Natural Science Foundation of Hebei Province of China (nos. E2014402099 and E2016402079) and Science and Technology Development Program of Handan (no. 1621211041-1).

\section{References}

[1] Y. Cheng, J. Tao, Y. Jiao, Q. Guo, and C. Li, "Influence of diatomite and mineral powder on thermal oxidative ageing properties of asphalt," Advances in Materials Science and Engineering, vol. 2015, Article ID 947834, 10 pages, 2015.

[2] J. Mikolaj, L. Remek, and M. Kozel, "Optimization of life cycle extension of asphalt concrete mixtures in regard to material properties, structural design, and economic implications," 
Advances in Materials Science and Engineering, vol. 2016, Article ID 6158432, 9 pages, 2016.

[3] S. M. Abtahi, S. Esfandiarpour, M. Kunt, S. M. Hejazi, and M. G. Ebrahimi, "Hybrid reinforcement of asphalt-concrete mixtures using glass and polypropylene fibers," Journal of Engineered Fibers and Fabrics, vol. 8, no. 2, pp. 25-35, 2013.

[4] S. Serin, N. Morova, M. Saltan, S. Terzi, and M. Karaşahin, "Prediction of the marshall stability of reinforced asphalt concrete with steel fiber using fuzzy logic," Journal of Intelligent and Fuzzy Systems, vol. 26, no. 4, pp. 1943-1950, 2014.

[5] A. García, J. Norambuena-Contreras, and M. N. Partl, "A parametric study on the influence of steel wool fibers in dense asphalt concrete," Materials and Structures/Materiaux et Constructions, vol. 47, no. 9, pp. 1559-1571, 2014.

[6] X. Qin, A. Q. Shen, and Y. C. Guo, "Experimental study on road performance of basalt fiber reinforced Bitumen mastics," Journal of Building Materials, vol. 19, no. 4, pp. 660-664, 2016 (Chinese).

[7] S. Tapkin and Ş. Özcan, "Determination of the optimal polypropylene fiber addition to the dense bituminous mixtures by the aid of mechanical and optical means," Baltic Journal of Road and Bridge Engineering, vol. 7, no. 1, pp. 22-29, 2012.

[8] Y. Kim and T.-S. Park, "Reinforcement of recycled foamed asphalt using short polypropylene fibers," Advances in Materials Science and Engineering, vol. 2013, Article ID 903236, 9 pages, 2013.

[9] Q. Guo, L. Li, Y. Cheng, Y. Jiao, and C. Xu, "Laboratory evaluation on performance of diatomite and glass fiber compound modified asphalt mixture," Materials and Design, vol. 66, pp. 5159, 2015.

[10] S. Oda, J. L. Fernandes Jr., and J. S. Ildefonso, "Analysis of use of natural fibers and asphalt rubber binder in discontinuous asphalt mixtures," Construction and Building Materials, vol. 26, no. 1, pp. 13-20, 2012.

[11] T. R. Herráiz, J. I. R. Herráiz, L. M. Domingo, and F. C. Domingo, "Posidonia oceanica used as a new natural fibre to enhance the performance of asphalt mixtures," Construction and Building Materials, vol. 102, pp. 601-612, 2016.

[12] P. J. Yoo and K.-H. Kim, “Thermo-plastic fiber's reinforcing effect on hot-mix asphalt concrete mixture," Construction and Building Materials, vol. 59, pp. 136-143, 2014.

[13] H. Chen and Q. Xu, "Experimental study of fibers in stabilizing and reinforcing asphalt binder," Fuel, vol. 89, no. 7, pp. 1616$1622,2010$.

[14] S. Qian, H. Ma, J. Feng, R. Yang, and X. Huang, "Fiber reinforcing effect on asphalt binder under low temperature," Construction and Building Materials, vol. 61, pp. 120-124, 2014.

[15] S. Tapkin, "The effect of polypropylene fibers on asphalt performance," Building and Environment, vol. 43, no. 6, pp. 1065-1071, 2008.

[16] N. Morova, S. Serin, S. Terzi et al., "Utility of polyparaphenylene terephtalamide fiber in hot mix asphalt as a fiber," Construction and Building Materials, vol. 107, pp. 87-94, 2016.

[17] H. Chen, Q. Xu, S. Chen, and Z. Zhang, "Evaluation and design of fiber-reinforced asphalt mixtures," Materials and Design, vol. 30, no. 7, pp. 2595-2603, 2009.

[18] Q. Xue, L. Liu, and Y.-J. Chen, "Study on the action effect of pavement straw composite fiber material in asphalt mixture," Construction and Building Materials, vol. 43, pp. 293-299, 2013.

[19] Q. Ye, S. Wu, and N. Li, "Investigation of the dynamic and fatigue properties of fiber-modified asphalt mixtures," International Journal of Fatigue, vol. 31, no. 10, pp. 1598-1602, 2009.
[20] S. Wu, Q. Ye, N. Li, and H. Yue, "Effects of fibers on the dynamic properties of asphalt mixtures," Journal Wuhan University of Technology, Materials Science Edition, vol. 22, no. 4, pp. 733-736, 2007.

[21] A. García, J. Norambuena-Contreras, M. Bueno, and M. N. Partl, "Influence of steel wool fibers on the mechanical, termal, and healing properties of dense asphalt concrete," Journal of Testing and Evaluation, vol. 42, no. 5, 2014.

[22] N. Morova, "Investigation of usability of basalt fibers in hot mix asphalt concrete," Construction and Building Materials, vol. 47, pp. 175-180, 2013.

[23] C. M. Gao, Microcosmic analysis and performance research of basalt fiber asphalt concrete [Ph.D. disseration], Jilin University, 2012 (Chinese).

[24] J. Fu, H. Liu, and Y. Cheng, "Mechanical parameter measuring and contrastive analysis on pavement performance of glass fiber reinforced bituminous mixtures," in Proceedings of the International Conference on Transportation Engineering, pp. 425-430, Chengdu, China, July 2007.

[25] P. Park, S. El-Tawil, S.-Y. Park, and A. E. Naaman, "Cracking resistance of fiber reinforced asphalt concrete at $-20{ }^{\circ} \mathrm{C}$," Construction and Building Materials, vol. 81, pp. 47-57, 2015.

[26] R. K. A. Al-Rub, T. You, E. A. Masad, and D. N. Little, "Mesomechanical modeling of the thermo-viscoelastic, thermo-viscoplastic, and thermo-viscodamage response of asphalt concrete," International Journal of Advances in Engineering Sciences and Applied Mathematics, vol. 3, no. 1, pp. 14-33, 2011.

[27] Z. You, Y. Liu, and Q. Dai, “Three-dimensional microstructuralbased discrete element viscoelastic modeling of creep compliance tests for asphalt mixtures," Journal of Materials in Civil Engineering, vol. 23, no. 1, pp. 79-87, 2011.

[28] Y. Liu and Z. You, "Accelerated discrete-element modeling of asphalt-based materials with the frequency-temperature superposition principle," Journal of Engineering Mechanics, vol. 137, no. 5, pp. 355-365, 2011.

[29] Y. Liu and Z. P. You, "Simulation of cyclic loading tests for asphalt mixtures using user defined models within discrete element method," Geotechnical Special Publication, vol. 179, pp. 742-749, 2008.

[30] Q. Dai and Z. You, "Prediction of creep stiffness of asphalt mixture with micromechanical finite-element and discrete-element models," Journal of Engineering Mechanics, vol. 133, no. 2, pp. 163-173, 2007.

[31] H. Wang and P. Hao, "Numerical simulation of indirect tensile test based on the microstructure of asphalt mixture," Journal of Materials in Civil Engineering, vol. 23, no. 1, pp. 21-29, 2011.

[32] H. N. Wang, Z. H. Huang, L. Li, Z. P. You, and Y. Chen, “Threedimensional modeling and simulation of asphalt concrete mixtures based on X-ray CT microstructure images," Journal of Traffic and Transportation Engineering, vol. 1, no. 1, pp. 55-61, 2014.

[33] H.-N. Wang, P.-W. Hao, and G.-Y. Lu, "Distribution properties of internal air voids in asphalt mixtures," Journal of Traffic and Transportation Engineering, vol. 9, no. 1, pp. 6-11, 2009.

[34] K. H. Moon and A. C. Falchetto, "Microstructural investigation of Hot Mix Asphalt (HMA) mixtures using Digital Image Processing (DIP)," KSCE Journal of Civil Engineering, vol. 19, no. 6, pp. 1727-1737, 2015.

[35] Z. Dong, X. Gong, L. Zhao, and L. Zhang, "Mesostructural damage simulation of asphalt mixture using microscopic interface contact models," Construction and Building Materials, vol. 53, pp. 665-673, 2014. 
[36] H. Wang, J. Wang, and J. Chen, "Micromechanical analysis of asphalt mixture fracture with adhesive and cohesive failure," Engineering Fracture Mechanics, vol. 132, pp. 104-119, 2014.

[37] A. Y. Yin, X. H. Yang, and Z. J. Yang, "2D and 3D fracture modeling of asphalt mixture with randomly distributed aggregates and embedded cohesive cracks," Procedia IUTAM, vol. 6, pp. 114-122, 2013.

[38] L.-Z. Song, Q.-F. Wang, G. Peng, and Y. Jiang, "Numerical simulation method for the domain with large number of random ellipse grains and their application," Chinese Journal of Computational Mechanics, vol. 29, no. 5, pp. 662-667, 2012.

[39] Q. Guo, Y. Bian, L. Li, Y. Jiao, J. Tao, and C. Xiang, "Stereological estimation of aggregate gradation using digital image of asphalt mixture," Construction and Building Materials, vol. 94, pp. 458466, 2015.

[40] I. Ioannis, H. Alma, G. Inna, S. Costas, and M. A. Almaadeed, "Micro-mechanical parameters in short fibre composite," Applied Composite Materials, vol. 21, no. 1, pp. 197-211, 2014.

[41] Y. Yu, J. Cui, and F. Han, "An effective computer generation method for the composites with random distribution of large numbers of heterogeneous grains," Composites Science and Technology, vol. 68, no. 12, pp. 2543-2550, 2008.

[42] T. Ma, Y. Zhang, H. Wang, X. Huang, and Y. Zhao, "Influences by air voids on the low-temperature cracking property of densegraded asphalt concrete based on micromechanical modeling," Advances in Materials Science and Engineering, vol. 2016, Article ID 6942696, 10 pages, 2016.

[43] X. F. Wang, Z. J. Yang, J. R. Yates, A. P. Jivkov, and C. Zhang, "Monte Carlo simulations of mesoscale fracture modelling of concrete with random aggregates and pores," Construction and Building Materials, vol. 75, pp. 35-45, 2015.

[44] D. Castillo and S. Caro, "Probabilistic modeling of air void variability of asphalt mixtures in flexible pavements," Construction and Building Materials, vol. 61, pp. 138-146, 2014.

[45] Z. J. Yang, X. T. Su, J. F. Chen, and G. H. Liu, "Monte Carlo simulation of complex cohesive fracture in random heterogeneous quasi-brittle materials," International Journal of Solids and Structures, vol. 46, no. 17, pp. 3222-3234, 2009.

[46] Q. L. Guo, Research on internal stress distribution of asphalt mixture and its impact on viscoelastic performance [Ph.D. thesis], Jilin University, Changchun, China, 2013 (Chinese).

[47] M. Pettinari and A. Simone, "Effect of crumb rubber gradation on a rubberized cold recycled mixture for road pavements," Materials and Design, vol. 85, pp. 598-606, 2015.

[48] EN, “Test methods for hot mix asphalt. Part 26: stiffness," EN 12697-26. Bituminous mixtures, British Standards Institution, London, UK, 2006.

[49] D.-Y. Wang, W.-L. Wu, X.-N. Zhang, J.-M. Yu, and Z. Li, "Numerical simulation of splitting test of asphalt mixture based on DIP-FEM," Journal of Jilin University (Engineering and Technology Edition), vol. 41, no. 4, pp. 968-973, 2011 (Chinese).

[50] A. E. Naaman and H. W. Reinhardt, "Proposed classification of HPFRC composites based on their tensile response," Materials and Structures/Materiaux et Constructions, vol. 39, no. 289, pp. 547-555, 2006.

[51] L. Ma and X. N. Zhang, "Comparison of HMA dynamic moduli between indirect tension and uniaxial compression test modes," Journal of Highway and Transportation Research and Development, vol. 26, no. 10, pp. 11-17, 2009.

[52] R. D. Peng, H. W. Zhou, H. W. Wang, and L. Mishnaevsky Jr., "Modeling of nano-reinforced polymer composites: microstructure effect on Young's modulus," Computational Materials Science, vol. 60, pp. 19-31, 2012.

[53] Y.-Q. Tan, L. Zhang, M. Guo, and L.-Y. Shan, "Investigation of the deformation properties of asphalt mixtures with DIC technique," Construction and Building Materials, vol. 37, pp. 581-590, 2012.

[54] H. Y. Katman, M. R. Ibrahim, M. R. Karim, S. Koting, and N. S. Mashaan, "Effect of rubberized bitumen blending methods on permanent deformation of SMA rubberized asphalt mixtures," Advances in Materials Science and Engineering, vol. 2016, Article ID 4395063, 14 pages, 2016.

[55] B. J. Putman and S. N. Amirkhanian, "Utilization of waste fibers in stone matrix asphalt mixtures," Resources, Conservation and Recycling, vol. 42, no. 3, pp. 265-274, 2004.

[56] H. F. Hassan and K. S. Al-Jabri, "Effect of organic fibers on open-graded friction course mixture properties," International Journal of Pavement Engineering, vol. 6, no. 1, pp. 67-75, 2005.

[57] Y. Zhang, Q. Guo, L. Li, P. Jiang, Y. Jiao, and Y. Cheng, "Reuse of boron waste as an additive in road base material," Materials, vol. 9, no. 6, article 416, 2016. 

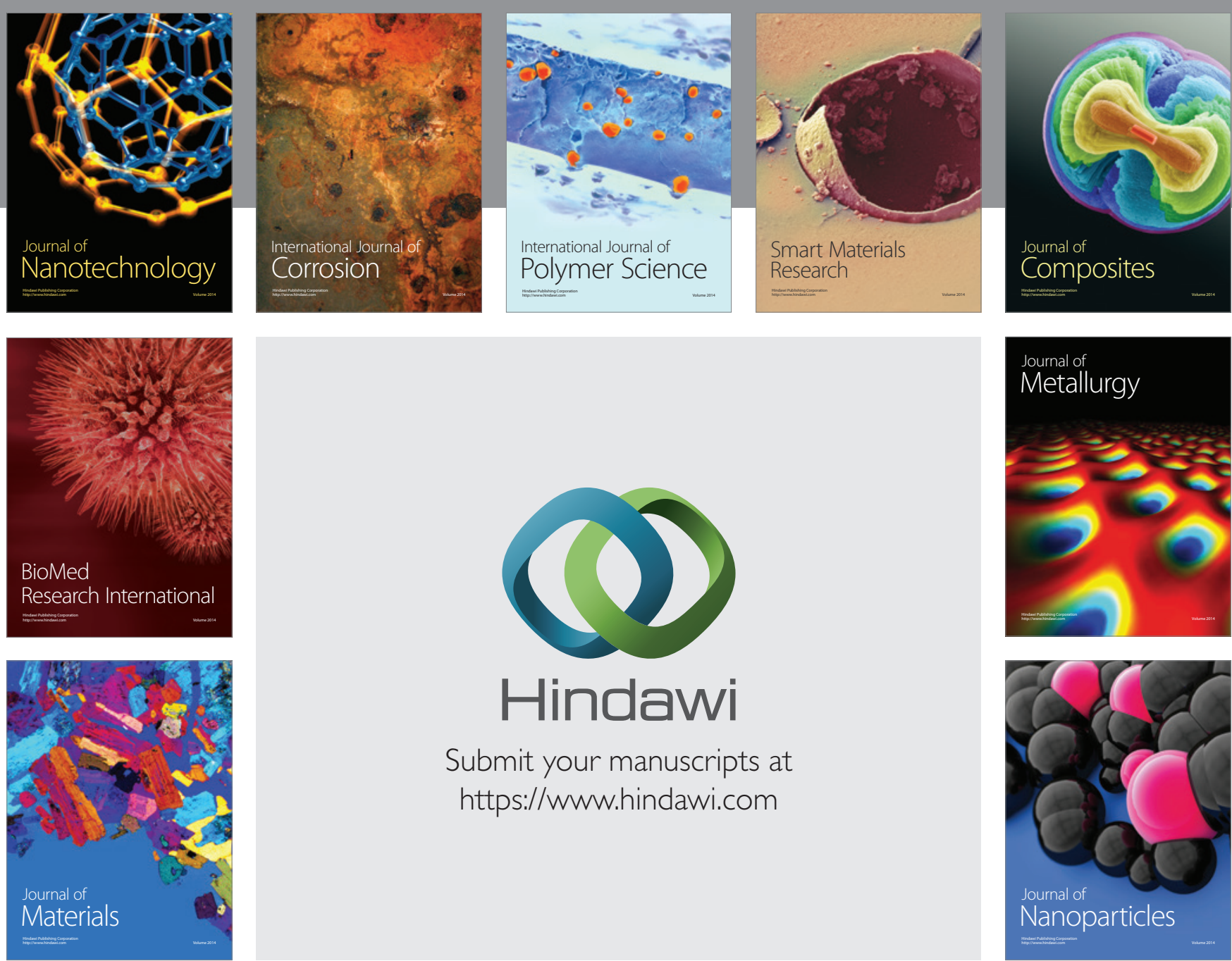

\section{Hindawi}

Submit your manuscripts at

https://www.hindawi.com

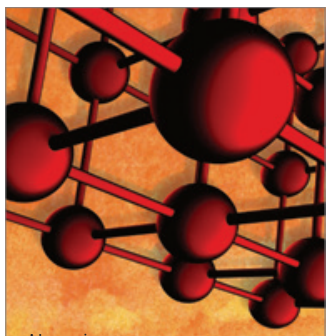

Materials Science and Engineering
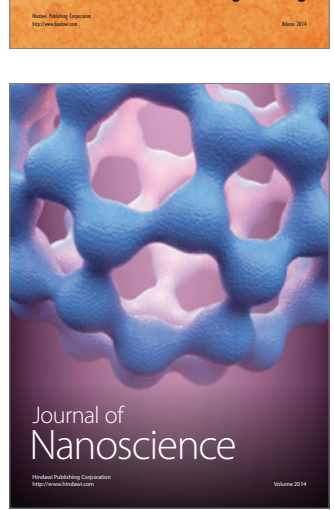
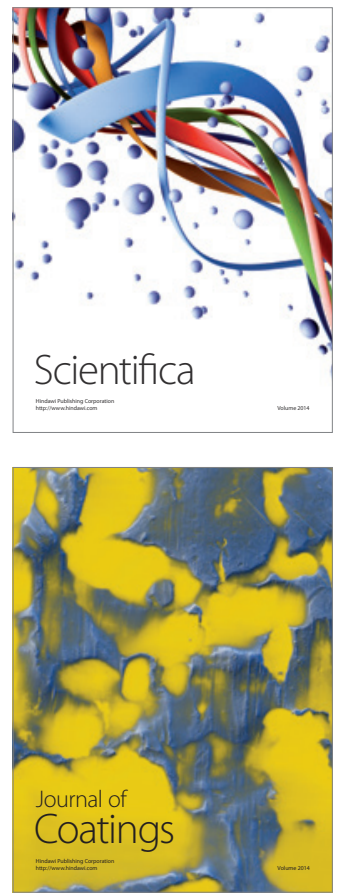
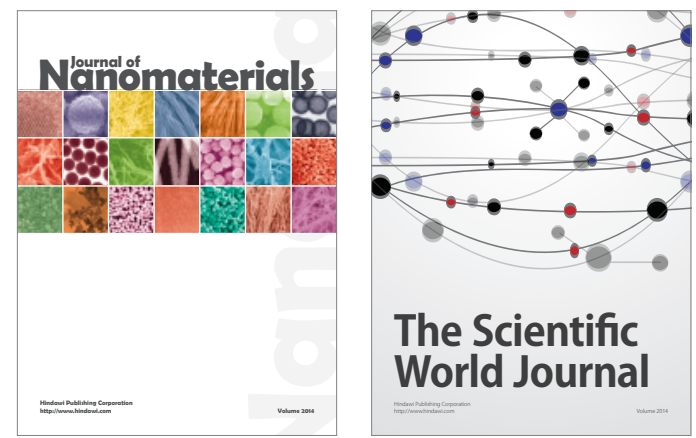

The Scientific World Journal
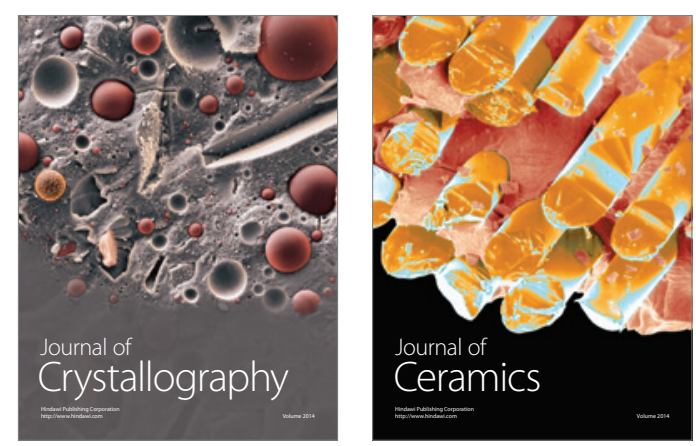
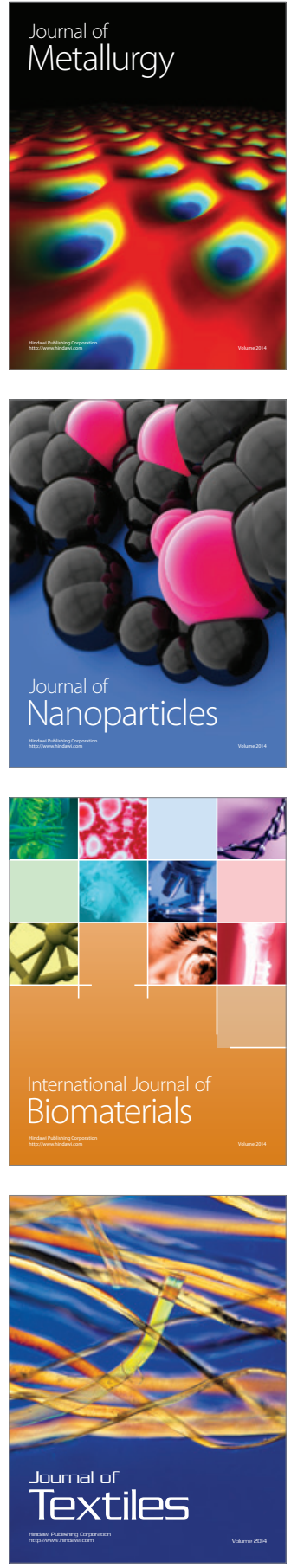